\title{
EDitorial
}

\section{Curriculum options: Being, knowing, and exploring}

\begin{abstract}
Andy Begg
Imagine school students developing confidence and connectedness, being actively involved in society and autonomous learning, and demonstrating abilities in thinking, using language, managing themselves, relating to others, and participating and contributing. Would society think that schools were achieving the major educational goals? Would they recognise the role of schools in this process? Would parents want to have these abilities measured and reported? Alternatively, are parents and society more concerned with reports, certificates, and grades for achievement in traditional school subjects?

Linked to these questions are two for educators: What is the relative importance of the vision, aims, and competencies compared with the importance of subject knowledge, and what should be done about it?

It is interesting to analyse The New Zealand Curriculum (Ministry of Education, 2007). The vision and key competencies statements are covered in three pages. The general discussion of learning areas (or subjects) covers about 11 pages. There are eight levels charts, each covering six pages, a total of 48 pages, presenting subject-based achievement objectives. One possible conclusion from this 3:11:48 page split is that the learning areas are nearly four times as important as the vision and competencies, and specific achievement objectives are more than four times as important as the process of and the general learning within each subject.

Faced with these weightings, together with the traditions of schooling and the currently accepted emphasis on assessment, only confident teachers are likely to significantly change the focus of their work. It seems the best that might be achieved in curriculum development is that some teachers might make some small changes as they work within subjects
\end{abstract}


to emphasise the vision and the competencies. Even as these teachers make changes, their efforts may be undermined by the assessment regime (school reporting and leaver qualifications) that affects schools. This emphasis on subject outcomes may be exacerbated by the fact that there are no achievement outcomes for competencies. Perhaps this is because assessment has traditionally been concerned with things (recall of facts and simple procedures that are remembered as though they were facts), while competencies are processes (described by verbs) - it is always easier to measure things than processes.

From my perspective the current assessment regime serves no educational purpose; indeed, our current assessment is demotivating. It tells students what they do not know and cannot do, rather than what they do know and can do, and it measures the outcomes of learning rather than the process. Assessment could be changed to focus primarily on formative purposes for guidance, and emphasise self-assessment (a desirable metacognitive thinking skill related to learning). Even within existing assessment traditions it is interesting to note how other educational systems emphasise more than traditional school subjects. For example, the French Baccalaureate examination includes a compulsory philosophy examination that focuses on thinking, while the International Baccalaureate Diploma schools include two compulsory subjects - thinking is addressed by "theories of knowledge" and participation, contribution, and service by "creative action and service" (K. Hara, personal communication, 12 August 2008).

During my time in education in New Zealand there have been official curriculum changes every 10 to 15 years, but these changes are only part of the real change process. Lead teachers have always explored possibilities and tried new alternatives, and when their explorations seem to be successful other teachers have followed (and finally the ideas are often accepted at the official level). Currently the Curriculum, with less specificity than its predecessor, is seen as encouraging exploration, though I am concerned that the emphasis on compliance, assessment, and reporting might work against this freedom.

The exploration of alternatives is vital for a number of reasons. Firstly, official curriculum change is influenced by what has been trialled rather 
than by what has been read about. Secondly, explorations upskill the explorers, and these explorers become resource people with practical skills who can work with colleagues on new possibilities. Thirdly, if the vision and competencies in the curriculum document are to be emphasised, groups of teachers will need to explore how this might be achieved within the New Zealand educational environment.

In the 1980s, under the auspices of the Department of Education, there were a number of exploratory studies encouraged at official, semiofficial, and informal levels by numerous curriculum officers. I was aware of such studies related to computing, science, mathematics, and women's studies. Typically these studies were based in a school or a cluster of schools, and some involved networks such as subject associations. Funding was not generous, but it encouraged the studies and meant that the movers and shakers were encouraged to try new ideas and discuss their work with others. Such initiatives could well be reinstated to help ensure curriculum development is ongoing, though this may need some relaxation of assessment requirements to allow more than minor explorations to occur.

All the papers in this issue are concerned with areas where further exploration within the local environment would be useful. The papers are concerned with subject-focused issues (thinking in hypertext, second languages, history, mathematics, and science), as well as more general issues (implications for preservice education, ethical knowhow, ontological centring, middle-years education, and integrating curriculum).

There is no need to wait for a Ministry of Education initiative to set up an exploratory study group, though recognition is always useful. There is no need to ensure that it has a research component, though this may be a useful way of gaining some academic input and obtaining funds. An exploratory study is a professional development activity, and all that is needed to start one is a group of keen people who want to try something different and are willing to talk about their project. Professional meetings and conferences such as those organised by subject associations and teacher unions, and publications such as teacher journals and this journal, provide conduits for discussion that in turn stimulate further exploration. 
In my editorial for the first edition of this journal (Begg, 2005), and in more recent work (Begg, 2008, p. 174), I have used the following figure to suggest that there are a number of mutually inter-related activities that co-emerge with curriculum. In conceptualising an exploratory study it is interesting to see how many of these are nearly always involved-some at the initial stages, some throughout the process, and some as a result. Indeed, I envisage such a model as suggesting components to consider when planning an exploratory study.

\section{FIGURE 1 EIGHT CO-EMERGING ACTIVITIES IN EDUCATIONAL DEVELOPMENT}

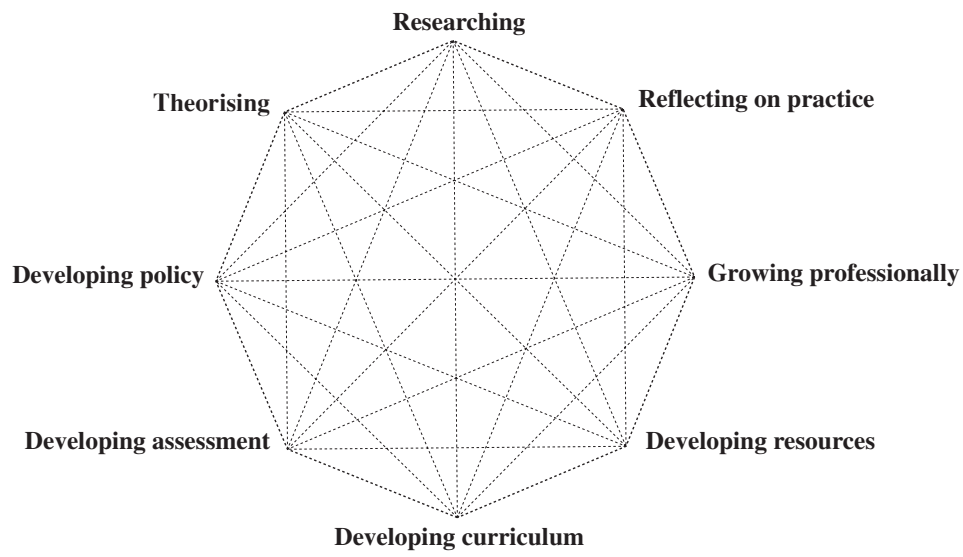

This diagram of the change model has its limitations. It needs to be seen as something that is influenced by the past, the present educational environment, and future possibilities. It is also multilevelledinternational, national or regional, school, and individual teacher. But, most importantly, it only addresses the professional aspects of change. There are personal and social dimensions within a teacher's life that need to be recognised (as we recognise these dimensions for students when planning curriculum). I see involvement in exploratory studies as providing opportunities for much more than professional growth.

My criticism of assessment-outcomes based rather than process basedis relevant when we consider curriculum change and exploratory studies. 
Involvement in the process means that as people we are developing. I enjoy the title (and the wonderful contents) of the book by Fromm (1979) To Have or To Be? Having things and having facts are measurable outcomes; being, becoming, exploring, growing, and developing are processes, and the value of these is in the process rather than in the outcome.

My vision for the future involves:

- increasing the emphasis on a living and changing curriculum rather than on a static one

- shifting the focus of assessment from summative to formative, and the control of it from teacher to students

- involving teachers and other concerned people in the exploration of alternatives

- emphasising the process dimension implied by the curriculum vision and the key competencies rather than factual knowledge and recall.

I accept that curriculum change takes time, but that means it is more important to ensure that the change is in the correct direction, and as there does not seem to be agreement about the direction, we at least need more exploration of the possibilities.

Finally, I wish to acknowledge the privilege it has been for me to have been the editor for the first four issues of Curriculum Matters. I have enjoyed wonderful support from the many contributors whose papers have stimulated my thinking, from the editorial board members who have reviewed the papers, and from colleagues at the New Zealand Council for Educational Research who have provided both professional and publishing support. I know it is time to hand on the mantle of editorship, and I wish my successor, Carol Mutch, all the best for the future.

\section{References}

Begg, A. (2005). Editorial: Why curriculum matters to me. Curriculum Matters, 1, $1-11$.

Begg, A. (2008). Emerging curriculum. Rotterdam: Sense Publications.

Fromm, E. (1979). To have or to be? London: Abacus.

Ministry of Education. (2007). The New Zealand curriculum. Wellington: Learning Media. 


\section{The author}

Andy Begg leads the postgraduate programme in the School of Education at Auckland University of Technology. He started his career in education as a high school teacher in 1963, was a textbook writer, then a government curriculum officer, before beginning work at universities in New Zealand and overseas. His research interests have focused on numerous aspects of curriculum and the related development process, and his current scholarship is about thinking in schools.

Email: andy.begg@aut.ac.nz 